\title{
E-cadherin and DAP kinase in pancreatic adenocarcinoma and corresponding lymph node metastases
}

\author{
TEMUUJIN DANSRANJAVIN ${ }^{1}$, CHRISTIAN MÖBIUS ${ }^{1}$, ANDREA TANNAPFEL ${ }^{2}$, MICHAEL BARTELS $^{1}$, \\ CHRISTIAN WITTEKIND $^{2}$, JOHAN HAUSS ${ }^{1}$ and HELMUT WITZIGMANN ${ }^{1}$ \\ ${ }^{1}$ Department of Surgery, University of Leipzig, Liebigstr 20a; ${ }^{2}$ Institute of Pathology, \\ University of Leipzig, Liebigstr 26, D-04103 Leipzig, Germany
}

Received April 1, 2005; Accepted July 18, 2005

\begin{abstract}
E-cadherin and DAP kinase have been implicated as 'invasion suppressor' genes in human cancer. The aim of this study was to analyze the methylation status of E-cadherin and DAP kinase and the expression of the protein in the metastatic lesions and to compare it with the expression in the primary tumor. Methylation-specific PCR of the DAP kinase and E-cadherin promoter was performed in 28 primary adenocarcinomas of the pancreas and in 13 corresponding regional lymph node metastases. The presence of E-cadherin and DAP kinase protein was assessed by immunohistochemistry. Metastatic lymph nodes showed a significant different expression profile from the primary tumor. E-cadherin methylation was observed in $8 / 28(29 \%)$ and loss of protein expression was observed in $16 / 28(57 \%)$ of pancreatic carcinomas. E-cadherin methylation was observed in $7 / 13$ $(54 \%)$ and loss of protein expression was observed in 11/13 $(85 \%)$ lymph node metastases $(\mathrm{p}=0.047)$. DAP kinase methylation occurred in 11/28 (39\%) pancreatic carcinomas and loss of protein expression was observed in 13/28 (46\%). DAP kinase was methylated in 6/13 (46\%) lymph node metastases and loss of protein expression was observed in 10/13 $(77 \%)(\mathrm{p}=0.039)$. Comparing primary tumor and corresponding lymph node metastases in 13 cases, the status of E-cadherin methylation was discordant in 2 cases. The protein expression pattern of E-cadherin and DAP kinase was discordant in 4 and 3 cases respectively. Unmethylated tumor samples did not express E-cadherin in 12 and DAP kinase protein in 6 cases. Our results demonstrate that reduction of E-cadherin and DAP kinase expression is more frequent in lymph node metastases than in the primary tumor and methylation of the promoter region contributes to this reduction; however, an alternative mechanism of inactivation seems to exist.
\end{abstract}

Correspondence to: Dr H. Witzigmann, Department of Surgery, University of Leipzig, Liebigstr 20a, D-04103 Leipzig, Germany

E-mail: helmut.witzigmann@medizin.uni-leipzig.de

Key words: gene silencing, methylation-specific PCR, immunohistochemistry, regional lymph node metastases

\section{Introduction}

Ductal adenocarcinoma of the pancreas is one of the leading causes of cancer-related deaths in Western countries, with a median survival of 4 to 6 months after diagnosis (1). One of the principal reasons for the poor survival rate is a high potential of pancreatic cancer cells to metastasize. Regional lymph node metastases are present at the time of diagnosis in more than $50 \%$ of patients with pancreatic cancer $(2,3)$. However, the molecular mechanisms involved in the metastatic invasion of lymph nodes in pancreas carcinogenesis are poorly understood at present. Multiple genetic alterations have been described including mutational activation of K-ras oncogenes and inactivation of tumor suppressor genes, Dpc4, p53, and p16 (4,5). Also, hypermethylation of gene promoters is a possible mechanism for gene inactivation. More than $50 \%$ of all human genes contain GC-rich DNA sequences within the promoter and first exon region (6). Aberrant methylation of the normally unmethylated $\mathrm{CpG}$ islands has been associated with transcriptional inactivation of cancer-related genes, including hMLH, p16, DAP kinase and E-cadherin (7-9).

E-cadherin is a transmembrane glycoprotein that mediates homotypic calcium-dependent cell-cell adhesion in epithelial tissue. It plays an important role in modulating the metastatic ability of various human tumors, such as gastric, cervical and nasopharyngeal cancer (10-12). In pancreatic cancer, downregulation of E-cadherin expression has been shown to be associated with advanced tumor stage and poor survival $(9,13,14)$.

Another gene reported to be regulated by methylation is DAP kinase, calcium-regulated serine/threonine kinase (15). The down-regulation of DAP kinase expression through hypermethylation of the promoter region has been demonstrated in cells derived from human breast, urinary bladder and renal cell carcinoma and in clinical specimens from lung and Bcell malignancies (16). The loss of DAP kinase expression was associated with metastatic potential in lung cancer (17).

Distant spread is the major cause of eventual treatment failure in patients suffering from pancreas carcinoma. To date, however, E-cadherin expression has only been investigated in primary tumors. The aim of this study was to evaluate the methylation status and protein expression of E-cadherin and DAP kinase in metastatic lesions and to compare it with the expression in the primary tumor. 


\section{Materials and methods}

We used paraffin-embedded tissue from 28 patients with ductal adenocarcinoma of the pancreas (17 men, 11 women; median age 63 years, range 46-76). In addition, we obtained cooresponding regional lymph node metastases with a high content of tumor cells $(>30 \%)$ from $13 \mathrm{pN} 1$ patients (patient: 2, 3, 5, 10, 11, 14, 15, 18, 19, 23, 24, 25, 28) (Table II). All patients were operated on with curative intent (R0 resection).

All of the patients underwent pancreatic surgery during the period of 1996 to 2001 in the Surgery Department (University of Leipzig). Staging and grading were performed according to the TNM classification of the International Union Against Cancer (UICC) and WHO criteria $(18,19)$.

The clinicopathological characteristics of the 28 patients are summarized in Table I. In all cases, the specimens were re-diagnosed and re-classified according to the new UICC classification system (18).

$M S P^{3}$ (methylation-specific PCR). Genomic DNA of each tumor was extracted from formalin-fixed, paraffin-embedded tissue blocks. Two 10- $\mu$ m-thick sections were cut from each block and placed into a microcentrifuge tube. Genomic DNA was isolated from paraffin-embedded tissue by digestion with $100 \mu \mathrm{g} / \mathrm{ml}$ proteinase $\mathrm{K}$ followed by standard phenolchloroform extraction and ethanol precipitation. Since it has been shown that formalin fixation and long-term storage may contribute to false-negative PCR as a result of DNA degradation, all unmodified DNA samples were examined for GAPDH-PCR (not shown).

DNA methylation patterns in the $\mathrm{CpG}$ islands of DAP kinase and E-cadherin genes were determined by chemical treatment with sodium bisulfite and PCR analysis. Treatment of DNA with sodium bisulfite converts unmethylated cytosines to uracil, producing sequence changes between methylated and unmethylated DNA. PCR primers that distinguish between these methylated and unmethylated DNA sequences were then used.

The bisulfite treatment was performed as follows: DNA $(2 \mu \mathrm{g})$ was denatured by adding $\mathrm{NaOH}$ to a final concentration of $0.3 \mathrm{M}$ and incubating for $15 \mathrm{~min}$ at $37^{\circ} \mathrm{C} .12 \mu \mathrm{l}$ of a $100 \mathrm{mM}$ hydroquinone (Sigma, St. Louis, MO) and $208 \mu 1$ of $3.6 \mathrm{M}$ bisulfite (Sigma) at pH 5.0 (both freshly prepared) were added and samples were incubated for $16 \mathrm{~h}$ at $55^{\circ} \mathrm{C}$. Modified DNA was purified using Wizard DNA purification resign (Promega Corp.) according to the manufacturer's instructions. Modification was completed by $\mathrm{NaOH}$ treatment (final concentration, $300 \mathrm{mM}$ ) for $15 \mathrm{~min}$ at $37^{\circ} \mathrm{C}$. The DNA was ethanol-precipitated, dried, resuspended in water, and stored at $-20^{\circ} \mathrm{C}$.

For each PCR reaction, 100 ng of bisulfite-modified DNA were amplified using the following primers. The primer sequences for unmethylated E-cadherin PCR were 5'-TAATT TTAGGTTAGAGGGTTATTGT-3' (sense) and 5'-CACAAC CAATCAACAACACA-3' (antisense), which amplify a 97-bp product; and for methylated E-cadherin PCR were 5'-TTAG GTTAGAGGGTTATCGCG-3' (sense) and 5'-TAACTAAA AATTCACCTACCGAC-3' (antisense), which amplify a 116-bp product (7). The primer sequences for unmethylated DAP kinase PCR were 5'-GGAGGATAGTTGGATTGAGTT-
Table I. Clinicopathological characteristics of 28 patients with pancreatic adenocarcinoma.

No. of patients (\%)

\begin{tabular}{ll}
\hline TNM stage $^{\mathrm{a}}$ & \\
I A & $3(10.7)$ \\
I B & $1(3.6)$ \\
II A & $6(21.4)$ \\
II B & $4(14.3)$ \\
III & $8(28.6)$ \\
IV & $6(21.4)$
\end{tabular}

pT categories ${ }^{a}$

pT1

pT2

pT3

pT4

Grading $^{\mathrm{b}}$

G1

G2

G3

Location

Head

25 (89.3)

Body

Tail

0

${ }^{\mathrm{a}}$ According to UICC (2002). ${ }^{\mathrm{b}}$ According to WHO (2000).

AATGTT-3' (sense) and 5'-CAAATCCCTCCCAAACACC AA-3' (antisense), which amplify a 106-bp product; and for methylated DAP kinase PCR were 5'-GGATAGTCGGATC GAGTTAACGTC-3' (sense) and 5'-CCCTCCCAAACGCC GA-3' (antisense), which amplify a 98-bp product (7).

PCR conditions consisted of denaturation at $94^{\circ} \mathrm{C}$ for $5 \mathrm{~min}$ followed by 40 cycles of denaturation at $94^{\circ} \mathrm{C}$ for $45 \mathrm{sec}$, primer annealing at temperatures from $58^{\circ} \mathrm{C}$ (methylated and unmethylated E-cadherin) and $60^{\circ} \mathrm{C}$ (methylated and unmethylated DAP kinase) for $45 \mathrm{sec}$, and primer extension at $72^{\circ} \mathrm{C}$ for $45 \mathrm{sec}$. Each PCR reaction $(20 \mu \mathrm{l})$ was loaded onto a $2 \%$ agarose gel and visualized under UV illumination. If a visible PCR product for both the unmethylated and methylated primers or methylated primer alone could be seen, the gene promoter was considered to be methylated.

DNA from the peripheral blood of healthy individuals that were positive for the E-cadherin and DAP kinase-unmethylated PCR reaction was used as an unmethylated positive control. The same DNA samples treated with SssI methyltransferase (Biolabs), which generates a completely methylated DNA at all $\mathrm{CpG}$ sites, were used as a methylation-positive control. Water blanks were also performed in all PCRs. Methylation negative samples were additionally verified by light cycler in real-time PCR in duplicate. 
Table II. Methylation and expression analysis of DAP kinase and E-cadherin in primary pancreas carcinoma (tumor) and lymph nodes (L. node).

\begin{tabular}{|c|c|c|c|c|c|c|}
\hline Patient no. & Grading & UICC & MSP E-cad. & Imm. & MSP DAPK & $\mathrm{Imm}$ \\
\hline 1 Tumor & 3 & I A & $\mathrm{u}$ & - & $\mathrm{m}$ & - \\
\hline 2 Tumor & 2 & IV & $\mathrm{u}$ & + & $\mathrm{m}$ & - \\
\hline 3 Tumor & 1 & IV & $\mathrm{u}$ & + & $\mathrm{u}$ & ++ \\
\hline 4 Tumor & 2 & II A & $\mathrm{u}$ & - & $\mathrm{m}$ & - \\
\hline 5 Tumor & 2 & III & $\mathrm{u}$ & ++ & $\mathrm{u}$ & + \\
\hline 6 Tumor & 2 & II A & $\mathrm{m}$ & - & $\mathrm{u}$ & + \\
\hline 7 Tumor & 3 & III & $\mathrm{u}$ & - & $\mathrm{u}$ & + \\
\hline 8 Tumor & 2 & II A & $\mathrm{m}$ & - & $\mathrm{u}$ & + \\
\hline 9 Tumor & 3 & II B & $\mathrm{u}$ & - & $\mathrm{u}$ & + \\
\hline 10 Tumor & 2 & III & $\mathrm{m}$ & - & $\mathrm{m}$ & - \\
\hline 11 Tumor & 2 & III & $\mathrm{u}$ & + & $\mathrm{m}$ & - \\
\hline 12 Tumor & 2 & II A & $\mathrm{u}$ & - & $\mathrm{u}$ & ++ \\
\hline 13 Tumor & 2 & IV & $\mathrm{u}$ & + & $\mathrm{u}$ & + \\
\hline 14 Tumor & 2 & III & $\mathrm{m}$ & - & $\mathrm{u}$ & + \\
\hline 15 Tumor & 2 & III & $\mathrm{u}$ & + & $\mathrm{m}$ & - \\
\hline 16 Tumor & 2 & I A & $\mathrm{m}$ & - & $\mathrm{u}$ & - \\
\hline 17 Tumor & 2 & IV & $\mathrm{u}$ & + & $\mathrm{u}$ & ++ \\
\hline 18 Tumor & 2 & III & $\mathrm{m}$ & - & $\mathrm{u}$ & - \\
\hline 19 Tumor & 3 & II B & $\mathrm{u}$ & - & $\mathrm{u}$ & - \\
\hline 20 Tumor & 2 & I B & $\mathrm{u}$ & + & $\mathrm{m}$ & - \\
\hline 21 Tumor & 2 & II A & $\mathrm{u}$ & + & $\mathrm{m}$ & - \\
\hline 22 Tumor & 3 & II A & $\mathrm{u}$ & + & $\mathrm{u}$ & ++ \\
\hline 23 Tumor & 2 & IV & $\mathrm{m}$ & - & $\mathrm{u}$ & + \\
\hline 24 Tumor & 2 & III & $\mathrm{u}$ & - & $\mathrm{m}$ & - \\
\hline 25 Tumor & 2 & II B & $\mathrm{m}$ & - & $\mathrm{m}$ & - \\
\hline 26 Tumor & 3 & IV & $\mathrm{u}$ & + & $\mathrm{u}$ & + \\
\hline 27 Tumor & 2 & I A & $\mathrm{u}$ & - & $\mathrm{m}$ & - \\
\hline 28 Tumor & 2 & II B & $\mathrm{u}$ & ++ & $\mathrm{u}$ & + \\
\hline 2 L. node & & & $\mathrm{m}$ & - & $\mathrm{m}$ & - \\
\hline 3 L. node & & & $\mathrm{u}$ & + & $\mathrm{u}$ & - \\
\hline 5 L. node & & & $\mathrm{m}$ & - & $\mathrm{u}$ & + \\
\hline 10 L. node & & & $\mathrm{m}$ & - & $\mathrm{m}$ & - \\
\hline 11 L. node & & & $\mathrm{u}$ & - & $\mathrm{m}$ & - \\
\hline 14 L. node & & & $\mathrm{m}$ & - & $\mathrm{u}$ & - \\
\hline 15 L. node & & & $\mathrm{u}$ & - & $\mathrm{m}$ & - \\
\hline 18 L. node & & & $\mathrm{m}$ & - & $\mathrm{u}$ & - \\
\hline 19 L. node & & & $\mathrm{u}$ & - & $\mathrm{u}$ & + \\
\hline 23 L. node & & & $\mathrm{m}$ & - & $\mathrm{u}$ & - \\
\hline 24 L. node & & & $\mathrm{u}$ & - & $\mathrm{m}$ & - \\
\hline 25 L. node & & & $\mathrm{m}$ & - & $\mathrm{m}$ & - \\
\hline 28 L. node & & & $\mathrm{u}$ & + & $\mathrm{u}$ & + \\
\hline
\end{tabular}

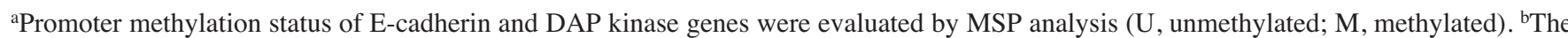
results in the immunohistochemistry were placed into three categories: absent (-), positive (+) and strong positive (++) depending on the percentage and intensity of immunoreactive tumor cells. 
Table III. E-cadherin methylation and loss of protein expression within primary tumors and lymph node metastases of pancreatic adenocarcinoma.

\begin{tabular}{lcr}
\hline & Primary tumor (\%) & LNM (\%) \\
\hline MSP & & \\
Methylated & $8 / 28(29)$ & $7 / 13(54)$ \\
Unmethylated & $20 / 28(71)$ & $6 / 13(46)$ \\
Imm. & & \\
Absent & $16 / 28(57)$ & $11 / 13(85)$ \\
Positive & $12 / 28(43)$ & $2 / 13(15)$ \\
\hline
\end{tabular}

MSP, methylation-specific PCR; Imm., immunohistochemistry; LNM, lymph node metastasis.

Immunohistochemistry. As previously described (21), the $5 \mu \mathrm{m}$ thick paraffin sections deparaffinated in xylene and rehydrated in graded alcohols were heated in a microwave oven 3 times for $5 \mathrm{~min}$ at $850 \mathrm{~W}$ in $10 \mathrm{mM}$ citrate buffer, $\mathrm{pH}$ 6.0. The slides were dipped into $98 \%$ methanol with $1 \% \mathrm{H}_{2} \mathrm{O}_{2}$ for 20 min to avoid a non-specific reaction due to endogenous peroxidase. After washing with PBS and pretreatment with $2 \%$ skim milk, slides were incubated at $37^{\circ} \mathrm{C}$ for $1 \mathrm{~h}$ with the primary antibodies (E-cadherin 1:50, DAP kinase 1:80). A rabbit polyclonal antibody raised against DAP kinase (Santa Cruz) and mouse monoclonal antibody against E-cadherin (Novocastra) were used.

The sections were run through the Biotin StreptavidinAmplified (B-SA) detection system (BioGenex). The immunoreaction was visualized by developing sections with AEC chromogene. Negative controls in which non-immune sera was substituted for the primary antibody were also included.

Only membranous staining of E-cadherin antibody was assessed for the scoring, since E-cadherin is an adhesion molecule located at the membrane. DAP kinase immunohistochemistry exhibited only cytoplasmic staining.

Qualitative and quantitative evaluation of the percentage of immunostained tumor cells and the intensity of staining were combined for scoring of E-cadherin and DAP kinase immunohistochemistry.

Quantitative evaluation: 1) 0-20\% of the tumor cells are positive, 2) $20-70 \%$ of tumor cells are positive, 3 ) over $70 \%$ of tumor cells are positive. Qualitative evaluation: (A) intense red staining, (B) light red staining, (C) no staining. The degree was scored as absent (1-B, 1-C), positive (2-A, 2-B) and strong- positive (3-A, 3-B).

Statistical analysis. For statistical analysis, the frequency of decreased expression and promoter methylation of E-cadherin and DAP kinase in node-negative and node-positive types of tumors, and in lymph node metastases was determined. Associations between variables were determined by $\chi^{2}$ analysis using a Statistical Package for the Social Sciences (SPSS/PC 9.0, Chicago). A $\mathrm{p}<0.05$ was defined as being statistically significant.

\section{Results}

E-cadherin. The results of E-cadherin MSP analysis are summarized in Table II. There was no evidence of homozygous deletion in the examined region, since all of the samples were amplified by PCR, either for methylated DNA or for unmethylated DNA. We detected a methylation of the E-cadherin promoter region in 8 of $28(29 \%)$ primary tumors and in 7 of 13 (54\%) lymph node metastases (Table III and Fig. 1a). Promoter methylation in primary tumors did not appear to be related to tumor stage, grade or lymph node status.

All tissue specimens were examined immunohistochemically to determine the relationship between E-cadherin promoter methylation and protein expression (Fig. 2a-c). Data obtained from E-cadherin immunohistochemistry are presented in Tables II and III.

The loss of E-cadherin protein expression was detected in $57 \%(16 / 28)$ of primary tumors and in $85 \%(11 / 13)$ of lymph node metastases (Table IV). The loss of E-cadherin was more frequent in lymph node metastases $(85 \%)$ compared to primary tumors $(57 \%)(\mathrm{p}=0.047)$.

None of the cases with promoter methylation showed Ecadherin staining in the immunohistochemistry. Of the samples with a loss of protein, 56\% (15 of 27) showed methylation of the E-cadherin gene promoter. However, in

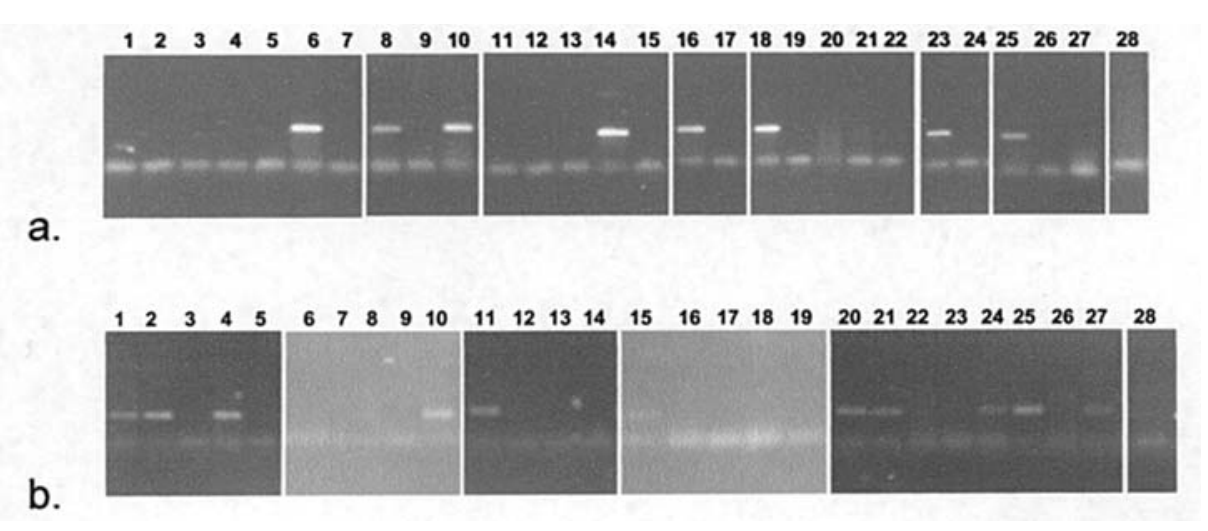

Figure 1. MSP analysis for methylated E-cadherin (a) and DAP kinase (b) gene promoters in primary and metastatic pancreatic carcinoma. 

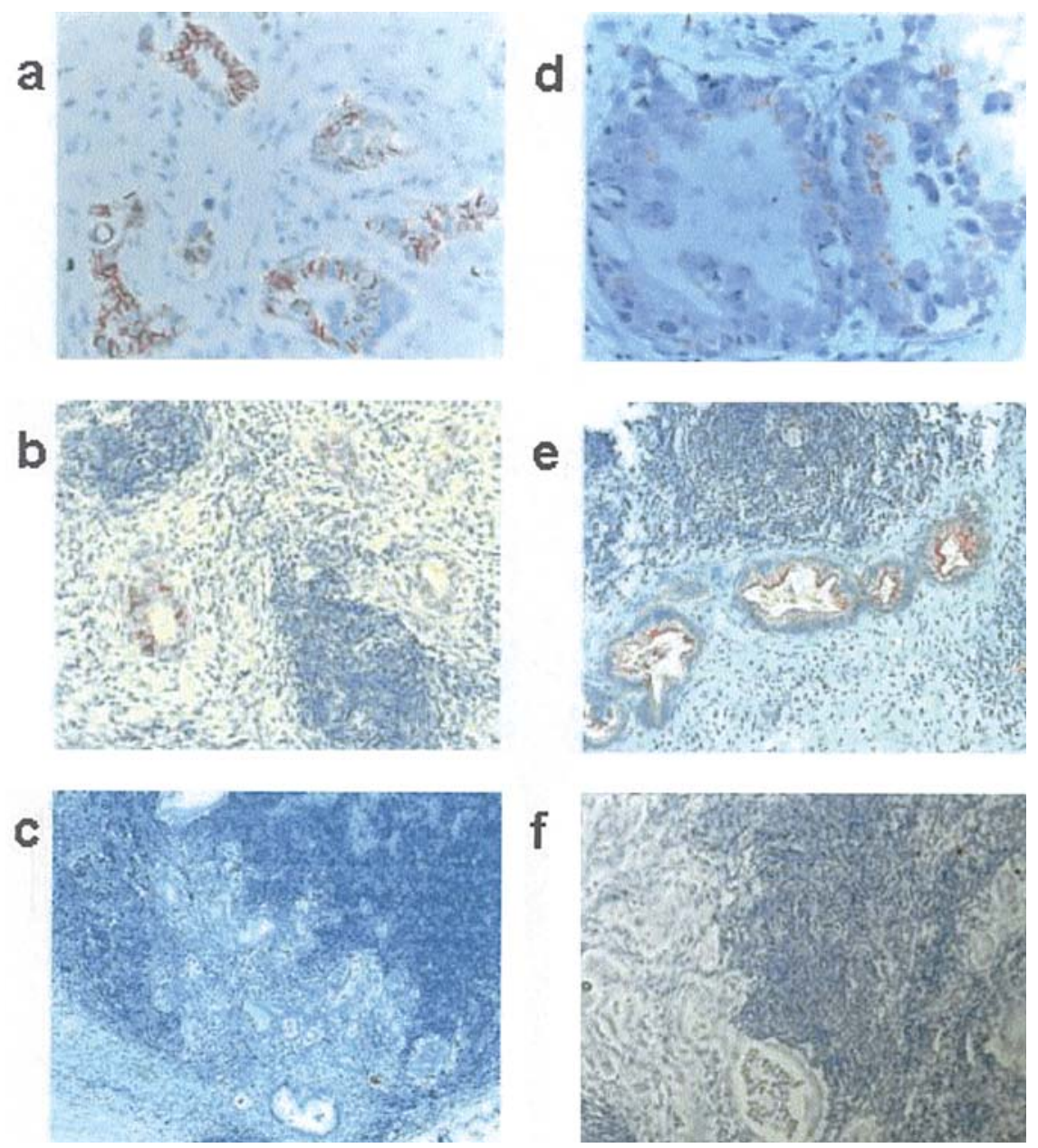

Figure 2. Expression pattern of E-cadherin and DAP kinase in primary and metastatic pancreatic carcinoma. E-cadherin expression in a primary tumor (a) and in lymph node metastasis (b), and loss of E-cadherin expression in lymph node metastasis (c) (a, original magnification x40; b and c, original magnification $\mathrm{x} 20$ ). DAP kinase expression in a primary tumor (d) and in lymph node metastasis (e), and loss of DAP kinase expression in lymph node metastasis (f) (d, original magnification $\mathrm{x} 40$; e and $\mathrm{f}$, original magnification $\mathrm{x} 20$ ).

Table IV. DAP kinase methylation and loss of protein expression within primary tumors and lymph node metastases of pancreatic adenocarcinoma.

\begin{tabular}{lcc}
\hline & Primary tumor $(\%)$ & LNM (\%) \\
\hline MSP & & \\
Methylated & $11 / 28(39)$ & $6 / 13(46)$ \\
Unmethylated & $17 / 28(61)$ & $7 / 13(54)$
\end{tabular}

Imm.

$\begin{array}{lrr}\text { Absent } & 13 / 28(46) & 10 / 13(77) \\ \text { Positive } & 15 / 28(54) & 3 / 13(23)\end{array}$

MSP, methylation-specific PCR; Imm., immunohistochemistry; LNM, lymph node metastasis.

12 samples ( 8 primary tumors, 4 lymph node metastases) the loss of E-cadherin expression was not associated with promoter methylation, indicating that there are alternative mechanisms of inactivation.
Among matched samples of primary tumors and lymph node metastases from 13 patients, concordant methylation of the E-cadherin promoter was observed in 5 cases whereas, in two cases, methylation of the E-cadherin promoter was found only in lymph node metastases and not in primary tumors (Table V).

In immunohistochemistry, the loss of E-cadherin expression was concordant in 7 cases. In 4 cases, only lymph node metastases revealed loss of E-cadherin expression whereas the corresponding primary tumors were positive for E-cadherin staining.

DAP kinase. Methylation of the DAP kinase gene promoter was detected in $39 \%(11 / 28)$ of primary tumors and in $46 \%$ (6/13) of lymph node metastases. In immunohistochemistry, the loss of DAP kinase protein expression was detected in $46 \%(13 / 28)$ of primary tumors and in $77 \%(10 / 13)$ of lymph node metastases (Table IV).

No correlation between DAP kinase protein expression and the clinicopathological characteristics of pancreatic cancer was observed. Moreover, lymph node metastases showed a higher frequency of DAP kinase protein loss compared to primary tumors $(\mathrm{p}=0.039)$. 
Table V. Promoter methylation and loss of protein expression of E-cadherin and DAP kinase in paired samples of primary tumors and corresponding lymph node metastases.

\section{Gene}

Primary tumor, $\mathrm{n}=13$ LNM, $\mathrm{n}=13$

\section{E-cadherin}

Promoter methylation

Loss of protein

\section{DAP kinase}

\begin{tabular}{llr} 
Promoter methylation & $6(46)$ & $6(46)$ \\
Loss of protein & $7(54)$ & $10(77)$ \\
\hline
\end{tabular}

All 17 cases (11 primary tumors, 6 lymph node metastases) with promoter methylation showed loss of DAP kinase expression. Of specimens with a loss of DAP kinase expression, 74\% (17/23) revealed promoter methylation. However, 6 unmethylated samples (2 primary tumors, 4 lymph node metastases) did not express DAP kinase, indicating that there are, at present, other unknown mechanisms of inactivation.

Amongst the 13 matched samples of primary tumors and corresponding lymph node metastases, each of the 6 patients who had methylated DAP kinase promoter in the lymph node metastasis had identical alterations in the primary tumor DNA (Table V). In immunohistochemistry, loss of DAP kinase expression was also detected in 7 paired lymph node metastases and primary tumors (Table V, Fig. 2d-f). In 3 cases, the loss of DAP kinase expression was obtained only in lymph node metastases and not in corresponding primary tumors.

\section{Discussion}

In this study, we provided evidence that the loss of E-cadherin expression and DAP kinase expression is significantly lower in metastatic lesions than in the primary tumor. To our knowledge, this has not previously been reported, but our findings are in accordance with other study groups. In our study, a down-regulation of E-cadherin expression was found only in lymph node metastases and not in corresponding primary tumor tissue in 4 cases. Two of these cases were associated with methylation of the E-cadherin promoter. This may reflect the discordant methylation pattern in different maturation stages of the same tumor cell lineage, as was recently demonstrated in paired pancreatic cancer cell lines and corresponding primary tumors (22). In this study, we found a significantly higher frequency of DAP kinase expression loss in lymph node metastases than in primary tumors of the pancreas. Among the matched samples of primary tumors and lymph node metastases, the loss of DAP kinase expression was subsequently obtained only in lymph node metastases and not in corresponding primary tumors in 3 cases. The results of this study support the proposition that DAP kinase inactivation is associated with the metastatic behavior of tumor cells. This data is consistent with in vivo studies demonstrating a suppressive role of DAP kinase expression for formation of metastases by increasing the occurrence of apoptosis (23). The loss of DAP kinase expression has been demonstrated to contribute to the formation of lung metastases and to be a positive selective advantage for metastasizing tumor cells (16). In squamous cell cancer, DAP kinase promoter methylation was significantly correlated with lymph node metastases (24).

Another possible explanation could be the accumulating evidence, from research at the cellular, chromosomal, and molecular genetic levels, that epithelial cancer is remarkably heterogenous. It is possible that the metastatic cells are subclones of the primary tumor which have lost E-cadherin and DAP kinase expression before they metastasize. As we know, down-regulation or complete shutdown of E-cadherin-mediated cell adhesion correlates with the loss of epithelial morphology and the acquisition of metastatic potential by the carcinoma cells in different tumors (25-28). In pancreatic cancer cell lines, the loss of E-cadherin/beta-catenin adhesion complex was shown to contribute to tumor progression (29).

In our series, $56 \%$ of samples with a loss of E-cadherin showed methylation of the E-cadherin gene promoter. This data confirmed the hypothesis that hypermethylation of $\mathrm{CpG}$ islands in the promoter region is one mechanism for loss of E-cadherin gene function, since mutations of the E-cadherin gene were rarely detected in human cancers (30). However, in twelve samples ( 8 primary tumors, 4 lymph node metastases) the loss of E-cadherin expression was not associated with promoter methylation, indicating a presence of alternative mechanisms of inactivation. The fact that $74 \%$ of cases with loss of DAP kinase expression showed methylation at the gene promoter supports the notion that promoter methylation might be an important mode of inactivation. Six unmethylated samples (2 primary tumors, 4 lymph node metastases) did not express DAP kinase, indicating also an alternative mechanism of inactivation. In accordance with other studies, our study suggests that promotor hypermethylation is the main mechanism involved in promotor silencing of E-cadherin and DAP kinase, although not the only one. Loss of heterozygosity and/or point mutation can also contribute to the downregulation of these two tumor suppressor genes (30).

In conclusion, the present study provides the first evidence that loss of E-cadherin and DAP kinase is significantly more frequent in metastatic lesions than in the primary tumor in pancreatic cancer. Promotor hypermethylation is one important event in silencing tumor suppressor genes but future studies, probably investigating the status of these two genes at different stages (e.g. premalignant versus malignant lesions), might help to understand the onset and underlying cause of inactivation.

\section{References}

1. Gudjonsson B: Carcinoma of the pancreas: critical analysis of costs, results of resections, and the need for standardized reporting. J Am Coll Surg 181: 483-503, 1995.

2. Van Heerden JA, ReMine WH, Weiland LH, McIlrath DC and Ilstrup DM: Total pancreatectomy for ductal adenocarcinoma of the pancreas. Mayo Clinic experience. Am J Surg 142: 308-311, 1981 .

3. Warshaw AL and Fernandez-del Castillo C: Pancreatic carcinoma. N Engl J Med 326: 455-465, 1992.

4. Moskaluk CA, Hruban RH and Kern SE: p16 and K-ras gene mutations in the intraductal precursors of human pancreatic adenocarcinoma. Cancer Res 57: 2140-2143, 1997. 
5. Lüttges J, Galehdari H, Brocker V, Schwarte-Waldhoff I, Henne-Bruns D, Klöppel G, Schmiegel W and Hahn SA: Allelic loss is often the first hit in the biallelic inactivation of the p53 and DPC4 genes during pancreatic carcinogenesis. Am J Pathol 158: 1677-1683, 2001.

6. Antequera $\mathrm{F}$ and Bird $\mathrm{A}$ : Number of $\mathrm{CpG}$ islands and genes in human and mouse. Proc Natl Acad Sci USA 90: 11995-11999, 1993.

7. Esteller M, Sanchez-Cespedes M, Rosell R, Sidransky D, Baylin SB and Herman JG: Detection of aberrant promoter hypermethylation of tumor suppressor genes in serum DNA from non-small cell lung cancer patients. Cancer Res 59: 67-70, 1999.

8. Tang X, Khuri FR, Lee JJ, Kemp BL, Liu D, Hong WK and Mao L: Hypermethylation of the death-associated protein (DAP) kinase promoter and aggressiveness in stage I non-small-cell lung cancer. J Natl Cancer Inst 92: 1511-1516, 2000.

9. Pignatelli M, Ansari TW, Gunter P, Liu D, Hirano S, Takeichi M, Kloppel $G$ and Lemoine NR: Loss of membranous E-cadherin expression in pancreatic cancer: correlation with lymph node metastasis, high grade, and advanced stage. J Pathol 174: 243-248, 1994.

10. Takeichi M: Cadherin cell adhesion receptors as a morphogenetic regulator. Science 251: 1451-1455, 1991.

11. Chen CL, Liu SS, Ip SM, Wong LC, Ng TY and Ngan HY: Ecadherin expression is silenced by DNA methylation in cervical cancer cell lines and tumours. Eur J Cancer 39: 517-523, 2002.

12. Tsao SW, Liu Y, Wang X, Yuen PW, Leung SY, Yuen ST, Pan J, Nicholls JM, Cheung AL and Wong YC: The association of E-cadherin expression and the methylation status of the E-cadherin gene in nasopharyngeal carcinoma cells. Eur J Cancer 39: 524-531, 2002.

13. Karayiannakis AJ, Syrigos KN, Chatzigianni E, Papanikolaou S, Alexiou D, Kalahanis N, Rosenberg T and Bastounis E: Aberrant E-cadherin expression associated with loss of differentiation and advanced stage in human pancreatic cancer. Anticancer Res 18: 4177-4180, 1998

14. Kuniyasu H, Ellis LM, Evans DB, Abbruzzese JL, Fenoglio CJ, Bucana CD, Cleary KR, Tahara E and Fidler IJ: Relative expression of E-cadherin and type IV collagenase genes predicts disease outcome in patients with resectable pancreatic carcinoma. Clin Cancer Res 5: 25-33, 1999.

15. Cohen O, Feinstein E and Kimchi A: DAP-kinase is a $\mathrm{Ca}^{2+} /$ calmodulin-dependent, cytoskeletal-associated protein kinase, with cell death-inducing functions that depend on its catalytic activity. EMBO J 16: 998-1008, 1997.

16. Kissil JL, Feinstein E, Cohen O, Jones PA, Tsai YC, Knowles MA, Eydmann ME and Kimchi A: DAP-kinase loss of expression in various carcinoma and B-cell lymphoma cell lines: possible implications for role as tumor suppressor gene. Oncogene 15: 403-407, 1997.

17. Inbal B, Cohen O, Polak-Charcon S, Kopolovic J, Vadai E, Eisenbach L and Kimchi A: DAP kinase links the control of apoptosis to metastasis. Nature 390: 180-184, 1997.
18. Sabia LH and Wittekind Ch: Pancreas. In: TNM Classification of Malignant Tumors (UICC). 6th edition. Sobin LH and Wittekind Ch (eds). New York, pp93-96, 2002.

19. Klöppel G, Hruban RH, Longnecker DS, Adler G, Kern SE and Partanen TJ: Ductal adenocarcinoma of the pancreas. In: WHO Classification of Tumors - Pathology and Genetics, Tumors of the Digestive System. Hamilton SR and Aaltonen LA (eds). IARC Press, Lyon, pp221-230, 2000.

20. Esteller M, Corn, PG, Baylin SB and Herman JG: A gene hypermethylation profile of human cancer. Cancer Res 61: 3225-3229, 2001.

21. Tannapfel A, Wasner M, Krause K, Geissler F, Katalinic A, Hauss J, Mossner J, Engeland K and Wittekind C: Expression of p73 and its relation to histopathology and prognosis in hepatocellular carcinoma. J Natl Cancer Inst 91: 1154-1158, 1999.

22. Ueki T, Walter KM, Skinner H, Jaffee E, Hruban RH and Goggins M: Aberrant CpG island methylation in cancer cell lines arises in the primary cancers from which they were derived. Oncogene 21: 2114-2117, 2002.

23. Zueva ES, Chevkina EM, Kimkhi A and Tatosian AG: Suppression of the metastatic potential of oncogene V-srctransformed cells as a result of activity of the exogenous DAP kinase. Mol Biol 36: 472-479, 2002.

24. Hasegawa M, Nelson HH, Peters E, Ringstrom E, Posner M and Kelsey KT: Patterns of gene promoter methylation in squamous cell cancer of the head and neck. Oncogene 21: 4231-4236, 2002.

25. Bringuier PP, Umbas R, Schaafsma HE, Karthaus HF, Debruyne FM and Schalken JA: Decreased E-cadherin immunoreactivity correlates with poor survival in patients with bladder tumors. Cancer Res 53: 3241-3245, 1993.

26. Siitonen SM, Kononen JT, Helin HJ, Rantala IS, Holli KA and Isola JJ: Reduced E-cadherin expression is associated with invasiveness and unfavorable prognosis in breast cancer. Am J Clin Pathol 105: 394-402, 1996.

27. Oka H, Shiozaki H, Kobayashi K, Inoue M, Tahara H, Kobayashi T, Takatsuka Y, Matsuyoshi N, Hirano S and Takeichi M: Expression of E-cadherin cell adhesion molecules in human breast cancer tissues and its relationship to metastasis. Cancer Res 53: 1696-1701, 1993.

28. Mbalaviele G, Dunstan CR, Sasaki A, Williams PJ, Mundy GR and Yoneda T: E-cadherin expression in human breast cancer cells suppresses the development of osteolytic bone metastases in an experimental metastasis model. Cancer Res 56: 4063-4070, 1996.

29. Lowy AM, Knight J and Groden J: Restoration of E-cadherin/ beta-catenin expression in pancreatic cancer cells inhibits growth by induction of apoptosis. Surgery 132: 141-148, 2002.

30. Hirohashi S: Inactivation of the E-cadherin-mediated cell adhesion system in human cancers. Am J Pathol 153: 333-339, 1998. 